\title{
Magnet-Sleeve-Sealed Mini Trochoidal-Gear Pump Prototype with Polymer Composite Gear
}

\author{
Pedro Javier Gamez-Montero ${ }^{1, *}$ (D) , Piotr Antoniak ${ }^{2}$, Robert Castilla ${ }^{1}$ (D), Javier Freire ${ }^{3}$, \\ Justyna Krawczyk $^{2}$, Jaroslaw Stryczek ${ }^{2}$ and Esteve Codina ${ }^{1}$ \\ 1 LABSON, Department of Fluid Mechanics, Universitat Politecnica de Catalunya, Campus Terrassa, \\ Colom 11, 08222 Terrassa, Spain; robert.castilla@upc.edu (R.C.); esteban.codina@upc.edu (E.C.) \\ 2 Fluid Power Research Group, Faculty of Machine Design Fundamentals and Tribology, Mechanical \\ Engineering Department, Wrocław University of Technology, Ul. Łukasiewicza 7/9, 50-371 Wrocław, Poland; \\ piotr.antoniak@pwr.edu.pl (P.A.); justyna.krawczyk@pwr.edu.pl (J.K.); jaroslaw.stryczek@pwr.edu.pl (J.S.) \\ 3 LABSON, Mechanical Engineering Department, Universitat Politecnica de Catalunya, Campus Terrassa, \\ Colom 11, 08222 Terrassa, Spain; javier.freire@upc.edu \\ * Correspondence: pedro.javier.gamez@upc.edu; Tel.: +34-93-739-8085
}

Received: 5 September 2017; Accepted: 19 September 2017; Published: 21 September 2017

\begin{abstract}
The trochoidal-gear technology has been growing in groundbreaking fields. Forthcoming applications are demanding to this technology a step forward in the conceiving stage of positive displacement machines. The compendium of the qualities and the inherent characteristics of trochoidal-gear technology, especially towards the gerotor pump, together with scale/size factor and magnetic-driven transmission has led to the idea of a magnet-sleeve-sealed variable flow mini trochoidal-gear pump. From its original concept, to the last phase of the design development, the proof of concept, this new product will intend to overcome problems such as noise, vibration, maintenance, materials, and dimensions. The paper aims to show the technological path followed from the concept, design, and model, to the manufacture of the first prototype, where the theoretical and numerical approaches are not always directly reflected in the prototype performance results. Early in the design process, from a standard-commercial sintered metal mini trochoidal-gear unit, fundamental characteristics and dimensional limitations have been evaluated becoming the strategic parameters that led to its configuration. The main technical challenge to confront is being sealed with non-exterior driveshaft, ensuring that the whole interior is filled and wetted with working fluid and helping the hydrodynamic film formation, the pumping effect, and the heat dissipation. Subsequently, the mini pump architecture, embodiment, methodology, materials, and manufacture are presented. The trend of applications of polymer composite materials and their benefits wanted to be examined with this new mini pump prototype, and a pure polyoxymethylene mini trochoidal-gear set has been designed and manufactured. Finally, both the sintered and the polymer trochoidal-gear units have been experimentally tested in an in-house full-instrumented mini test bench. Although the main goal of the presented work is the development of a new mini trochoidal-gear pump prototype rather than a numerical study, the results have been compared with numerical simulation. Subsequently, the prototype of the mini trochoidal-gear pump is a feasible proof of concept supported by functional indexes and the experimental results.
\end{abstract}

Keywords: mini gerotor; trochoidal-gear technology; pump configuration; advanced design; performance modeling; polymer composite; manufacturing; magnetic driving; fluid power

\section{Introduction}

The trochoidal-gear technology has been growing in groundbreaking areas, such as life science (pharmaceutical and biomedicine) and its presence is becoming more usual in the last years [1]. 
Low-pulsation flow ripple, together with simplicity and versatility, are inherent characteristics behind the significant launch of the trochoidal-gear technology towards pumps.

Forthcoming applications, such as the direct dosing in exact quantity, maximum spraying, and precision in their location over the plant in agriculture sector, are demanding trochoidal-gear technology to take a step forward in the conceiving stage of new pumps. Here, the Academia can make contributions with substantial knowledge of the whole process, not only by the numerical approach and performance analysis of existing units, but also in the prototype development and manufacturing of new-born units, which is not minor work, and the expected know-how is of great value.

By reviewing the current state in the research field of hydraulic gear machines, a great amount of works have been published, especially the reference book of Ivantysyn and Ivantysynova [2]. The consulted literature reveals that trochoidal-gear studies are mainly theoretical methodologies, numerical approaches, and simulations corroborated with experimental validation in existing units, especially projects in collaboration with an industrial partner that is the manufacturer. Nevertheless, a lack of works devoted to the development of a trochoidal-gear (gerotor) pump from scratch is revealed [3].

The authors, predominantly, would like to focus on the most recent open literature of the last three-year period due to the constant and fast progress of the research area. With regard to hydraulic pumps in this period, the significant publications are mainly devoted to lubricating, deformation, and leakage performance, among others, in an external gear pump [4], crescent pump [5], combination of external gear pump, and gerotor pump [6].

With regard to trochoidal-gear pumps, the novel investigations are primarily related to numerical studies validated with experimental methodology. Altare and Rundo $[7,8]$, in their new published works, present an advance in the understanding of gerotor pump technology through the simulation approach, among others, in suction capability, port plate shape, and inlet pipe location. Moreover, the deformation of the cover is studied, revealing two important consequences: the increment of the leakages and the generation of an additional volume variation, which alters the pressure ripple. The work of Pellegri et al. $[9,10]$ is devoted to the comparison of two numerical approaches and their agreement with experimental results under proper assumptions. Frosina et al. [11] focused their work in the analysis of geometrical effects of a lubrication gerotor pump, validated with experimental pressure oscillations. On the other hand, cavitation phenomenon under particular operation conditions of a lubrication gerotor pump of an internal combustion engine is investigated in Buono et al. [12] by monitoring experimental work.

Undoubtedly, a combination of theoretical and numerical methods to guide the designer in an early stage of the design process is recommendable, even indispensable. Nonetheless, from the initial concept to the first prototype there is an arduous and sinuous journey, where the theoretical approach is not always directly reflected in the prototype performance results. These first results will be taken as a frame of reference of this new-born and proof of concept [13].

With regard to experimental procedure, non-invasive visualization techniques are being widely used in recent published works such as Stryczek et al. [6], Garcia-Vilchez et al. [14], and Raush et al. [15]. This current experimental research, at different extend and achievement, pursues to be a validation tool of the numerical modeling results.

Other key publications are related to reduce contact stress by new variable clearance strategies that diminish collisions in Hsieh [16] by changing the geometric parameters of the trochoidal gearing teeth profile in Ivanović et al. [17,18] and profile design in hydrostatic units in Nag and Maiti [19]. As a versatility sign of trochoidal-gear units, the hydraulic flow ripple cancellation by using the primary flow source has been investigated by O'Shea [20]. The implementation of a feed-forward motor torque control algorithm reduces flow ripple, and therefore pressure ripple, by influencing the speed of a relatively high volumetric displacement low-inertia pump, a gerotor pump, through open loop control of the driving motor torque. The gerotor pumps, as compared to some other displacement units, have been found to have a ripple profile that is dominated by the fundamental pumping harmonic. 
Another example is the GeroMAG concept, a non shaft-drive gerotor pump with magnetic-driving outer rotor [13] with the advantages of magnetic power transmission [21].

The trend of the applications of polymer composite materials instead of metals is being gradually introduced in fluid power elements, as shown in Stryczek et al. [22]. The work presented by Stryczek et al. [23] was undoubtedly a step forward in the gerotor pump technology manufacturing a polyoxymethylene (POM) trochoidal-gear set and researching by means of a computational model how the stress and deformations are influenced by the design factors. Another remarkable work has been carried out by Mancini et al. [24] with their study of polyphthalamide/glass-fiber and polyphthalamide/glass-fiber/polytetrafluoroethylene-based composites as substitutes for aluminum and steel, respectively, in the production of motorcycle oil gerotor pump parts (housing, shaft/inner, and outer gear). Experimental curves were obtained by monitoring gerotor pump pressure, speed, flow rate and temperature in a $150 \mathrm{cc}$ motorcycle, with the engine rotation increasing from zero to its maximum of about 11,200 rpm. Numerical mechanical analyses are performed and results suggest that mechanical properties and stresses generated can withstand with pressure up to 1.8 bar. Unfortunately, volumetric efficiency indexes are not reported. Rodinov and Rekadze [25] performed an experimental vibroacustic study in spur gear pumps with different materials concerning the noise. The driven and driver/shaft gear were made of different composite materials and the case with stainless steel. As a result, it can be stated that materials with lower strength characteristics radiate less noise and vibration. Regrettably, durability and volumetric efficiency indexes are not reported.

The next topic to be covered is the scale, the miniature size although not being micro size, where few studies are available in the open literature regarding trochoidal-gear pumps with the exception of Mancò et al. [26]. In small scales, the current knowledge, design criteria, and know-how used in conventional sizes become questionable, as it is conditioned by the demanding axial and radial clearances, as it has also recently been evidenced by Gamez-Montero et al. [27], Castilla et al. [28], and this present work.

The compendium of the qualities of trochoidal-gear technology, gerotor pump versatility, polymer composite materials, and the scale/size factor, together with magnetic-driven transmission has led to the idea of a magnet-sleeve-sealed mini trochoidal-gear pump (mTGp). From its original concept to the last phase of the design development, the prototype, this new product mTGp intends to overcome problems such as noise, vibration, maintenance, materials, and dimensions. The paper aims to show the technological path followed from the concept, design, and model to the manufacture of the first prototype, where the analytical and simulation studies are not always directly mirrored in the prototype performance indexes.

Thus, the aim of the mini trochoidal-gear pump is to achieve an average volumetric flow rate at a low rotational speed with satisfactory volumetric efficiency together with being leakage-free (sleeve sealed) and reducing air-borne noise (compact and polymer material). The configuration of the mini trochoidal-gear pump, as a variable flow pump operating powered by a magnet-sleeve brushless motor profiting the configuration, will be able to influence future applications, among others, domestic and mobile hydraulic packs.

As far as authors' knowledge, such technological proposals have not been shown, not yet proving viability. Subsequently, the prototype of the mini trochoidal-gear pump is a feasible proof of concept supported by functional indexes and experimental results.

\section{The Mini Trochoidal-Gear Pump Prototype}

Basically, a trochoidal-gear pump is an internal gear pump, also known as gerotor pump, with a couple of mated trochoidal-gears so that each tooth is always in sliding contact. The process of pumping is carried out when the rotational movement of the gear set creates circulation of increasing volumes from the inlet to the outlet port of the pump. 


\subsection{The Mini Trochoidal-Gear Unit}

\subsubsection{A Trochoidal-Gear Set}

A trochoidal-gear set of a gerotor pump is a pair of gears with a trochoidal-teeth profile: inner/internal and outer/external gears (see Figure 1). The two gears are mated so that each tooth of the inner gear is always in sliding contact with a tooth of the outer gear, and interteeth contact occurs. Both gears rotate in the same direction but at different speeds because of the external gear has one tooth more than the inner gear, and consequently, the inner gear is slightly faster than the outer gear.

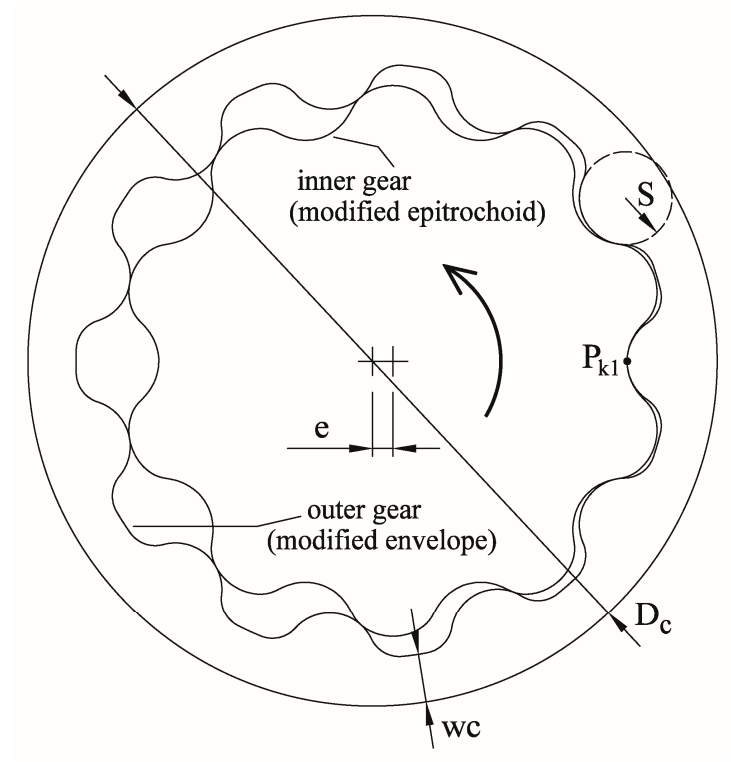

Figure 1. Basic geometrical parameters of the trochoidal-gear set.

\subsubsection{Model of the Mini Trochoidal-Gear Unit}

In a different approach from previous authors' works [13], the authors required in this work to conceive the mini trochoidal-gear unit by using a standard-commercial trochoidal-gear set widely use, among others, in in-line and in-tank fuel pumps. Although very basic information can be obtained from the specification data sheet of such pumps, it could be taken as a frame of reference in the proposed concept of a mini trochoidal-gear pump.

An extensive study of available sheet commercial literature shows a great number of standard trochoidal-gear sets, and each application has to be adapted to fit one of them. However, the selection of the design parameters that has led to the geometry of these standard sets is not clear, at least in the available information sheets. In this work, the design parameters of the selected standard trochoidal-gear set that characterizes the performance of contact stress, volumetric characteristics, and flow irregularity are investigated by means of GeroLAB Package System [29], along with the authors' methodology based on best practice rules [3].

By accurately measuring the selected standard trochoidal-gear set of $Z=11$ outer gear teeth, the dimensional constraints, see Figure 1, of thickness $H$ in $[\mathrm{mm}]$, the external diameter of outer gear $D_{c}$ in $[\mathrm{mm}]$, and the wall wide of the outer gear $w c$ in $[\mathrm{mm}]$ are introduced in the Design module of the GeroLAB 2.0 software, as shown in Figure 2. The characterization of the system implies a standard volumetric flow rate that can be calculated by the volumetric capacity $c_{v}$ in $\left[\mathrm{cm}^{3} / \mathrm{rev}\right]$. 


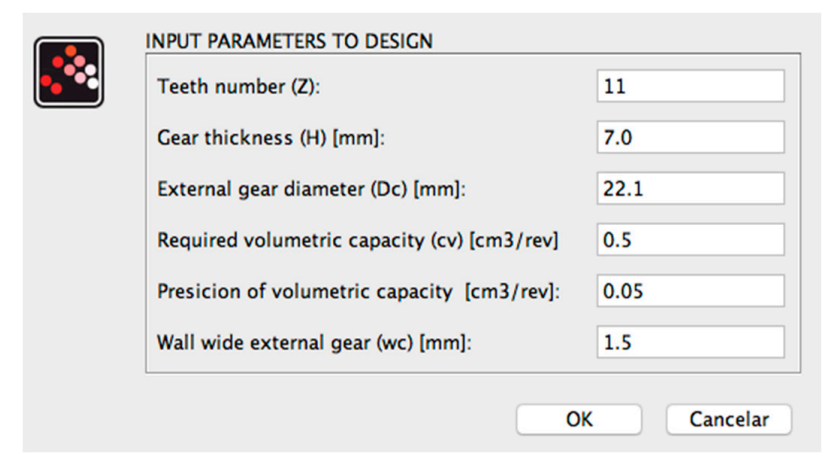

Figure 2. Design module basic parameters in GeroLAB Package System [29].

The characteristics of the mini-trochoidal gear be additionally evaluated by taking the formerly published author's own procedure. The eccentricity $e$ in $[\mathrm{mm}]$ of the trochoidal-gear set can be first evaluated by using a heuristic approach to the equation,

$$
e^{2}-\left(0.25 D_{c}-0.5 w c\right) e+39.8 \frac{C_{v}}{H}=0
$$

where $w c$ is calculated as follows,

$$
w c=0.075 D_{c}
$$

being just an estimation because it is not taking into account the number of teeth of the outer gear, working pressure, contact stress, and gear material. Now, the arc radius of the outer gear tooth $S$ in $[\mathrm{mm}]$ can be calculated as (see Figure 1):

$$
S=\frac{Z e}{\lambda}-0.995\left(0.5 D_{c}-w c\right)+2 e
$$

where $\lambda$ is the tooth profile height correction coefficient-function of the eccentricity, the number of teeth, the arc radius of the outer gear tooth, and the tip diameter of the inner gear-with recommended values going from 0.6 (larger $S$ ) to 0.8 (shorter $S$ ) [23].

The theoretical torque $T$ in $[\mathrm{N} \cdot \mathrm{m} / \mathrm{bar}]$, theoretical power $\mathrm{N}$ in $[\mathrm{W} / \mathrm{bar} \cdot \mathrm{rpm}]$, the tip velocity of the internal gear $V t$ in $[\mathrm{m} / \mathrm{s} \cdot \mathrm{rpm}]$, and the theoretical radial load $R L$ in $[\mathrm{N} / \mathrm{bar}]$ can be estimated by using the following expressions:

$$
\begin{gathered}
T=0.016 c_{v} \\
N=0.0016 c_{v} \\
V t=0.0001\left(0.5 D_{c}-w c-e\right) \\
R L=0.1 H\left(D_{c}-2 w c-3 e\right)
\end{gathered}
$$

Finally, the mini trochoidal-gear figures are abridged in Table 1.

Table 1. Specifications of the mini trochoidal-gear unit.

\begin{tabular}{cc}
\hline Parameter & Value \\
\hline$c_{v}$ & $0.48 \mathrm{~cm}^{3} / \mathrm{rev}$ \\
$H$ & $7 \mathrm{~mm}$ \\
$D_{c}$ & $22.1 \mathrm{~mm}$ \\
$w c$ & $1.5 \mathrm{~mm}$ \\
$e$ & $0.66 \mathrm{~mm}$ \\
$Z$ & 11 \\
$S$ & $1.5 \mathrm{~mm}$ \\
$T$ & $0.008 \mathrm{~N} \cdot \mathrm{m} / \mathrm{bar}$ \\
$N$ & $0.0008 \mathrm{~W} / \mathrm{bar} \cdot \mathrm{rpm}$ \\
$V t$ & $0.0009 \mathrm{~m} / \mathrm{s} \cdot \mathrm{rpm}$ \\
$R L$ & $12 \mathrm{~N} / \mathrm{bar}$ \\
\hline
\end{tabular}




\subsubsection{Profiles of the Mini Trochoidal-Gear Unit}

Previously, geometric and characteristics of the trochoidal-gear unit were set, and now the well-stablished expressions to draw the trochoidal profiles (see Figure 3) are used by means of the free software GeroLAB [30].

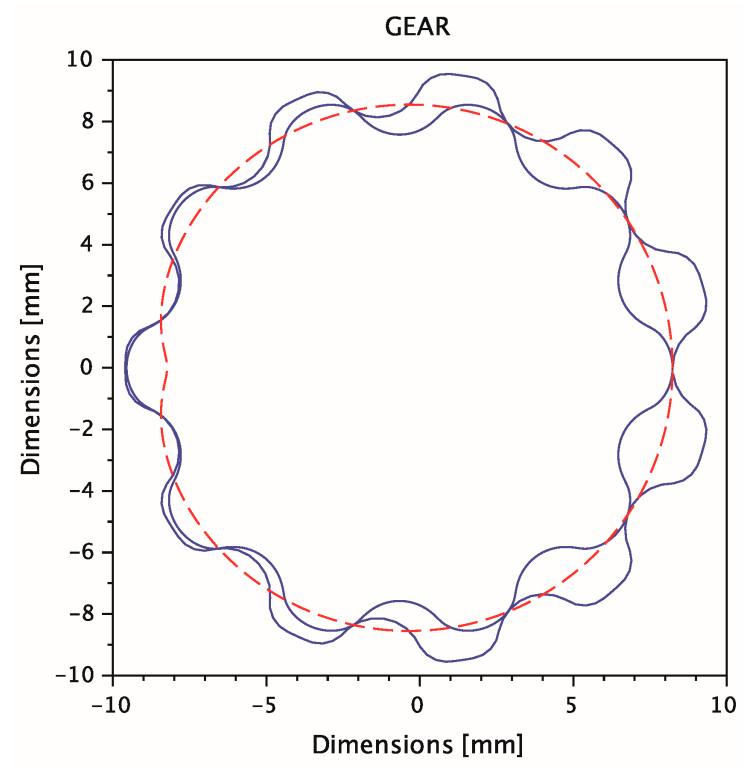

Figure 3. Mini trochoidal-gear profiles and line of contact by using GeroLAB [30].

\subsubsection{Materials and Manufacture of the Mini Trochoidal-Gear Unit}

A first unit of the mini trochoidal-gear set has been manufactured by Aleaciones de Metales Sinterizados (AMES) of sintered metal material. The powder metallurgical material follows the requirements and specifications of the standard ISO 5755:2012 owing to its combination of hardness and mechanical strength.

The gear set has a tolerance grade of trochoidal tip-clearance from 10 to $64 \mu \mathrm{m}$ to achieve precise rotation, together with a precision thickness of $40 \mu \mathrm{m}$ and a surface roughness of $0.4 \mathrm{Ra}$.

The trend of applications of polymer composite materials and their benefits wanted to be examined with the mTGp. Based on the analysis of the mini trochoidal-gear unit, working operation, and expertise of Stryczek et al. [31], the decision of choosing as polymer composite material the pure polyoxymethylene ( $\mathrm{POM})$ is grounded on the following characteristics: high strength and rigidity, its accessibility on the market, low price, and among other things, its handling by means of the injection molding; summarizing, its average characteristics and qualities are presented in Table 2. The mini trochoidal-gear POM set has been manufactured by the Fluid Power Research Group at Wrocław University of Technology, and it is shown in Figure 4.

Table 2. Polyoxymethylene characteristics of [31].

\begin{tabular}{cc}
\hline Parameter & Value \\
\hline Yield point & $60 \mathrm{MPa}$ \\
Elasticity modulus & $3000 \mathrm{MPa}$ \\
Linear elongation factor & $10 \times 10^{-5} / \mathrm{K}$ \\
Water absorptivity & $0.7 \%$ \\
Contraction & $0.0285 \mathrm{~cm} / \mathrm{cm}$ \\
\hline
\end{tabular}




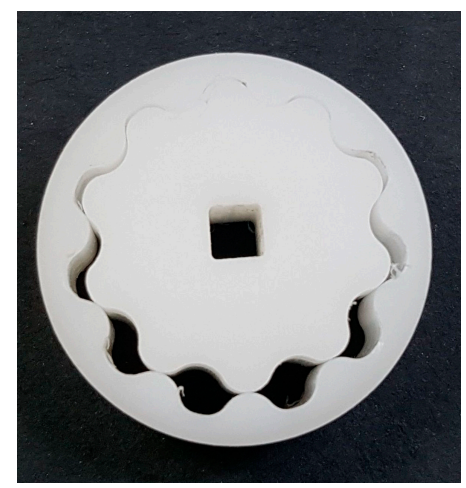

Figure 4. Mini trochoidal-gear polyoxymethylene (POM) set.

\subsection{The Mini Trochoidal-Gear Pump Architecture}

The mini trochoidal-gear pump architecture embodies the mini trochoidal-gear set, the magnetic-driving motor, and the pump body and covers. This configuration of the pump is compact and sealed without the exterior driveshaft.

Figure 5 depicts the preliminary pump design as a technology demonstration by means of the construction of a prototype with three main elements: the magnet stator, the pump body, and the pump cover. The pump body includes the inlet and outlet ports without the metering porting with grooves owing to the special design of the damping outlet port and the possibility of bi-directional work. The depth of the porting is such that it does not restrict the pump flow.

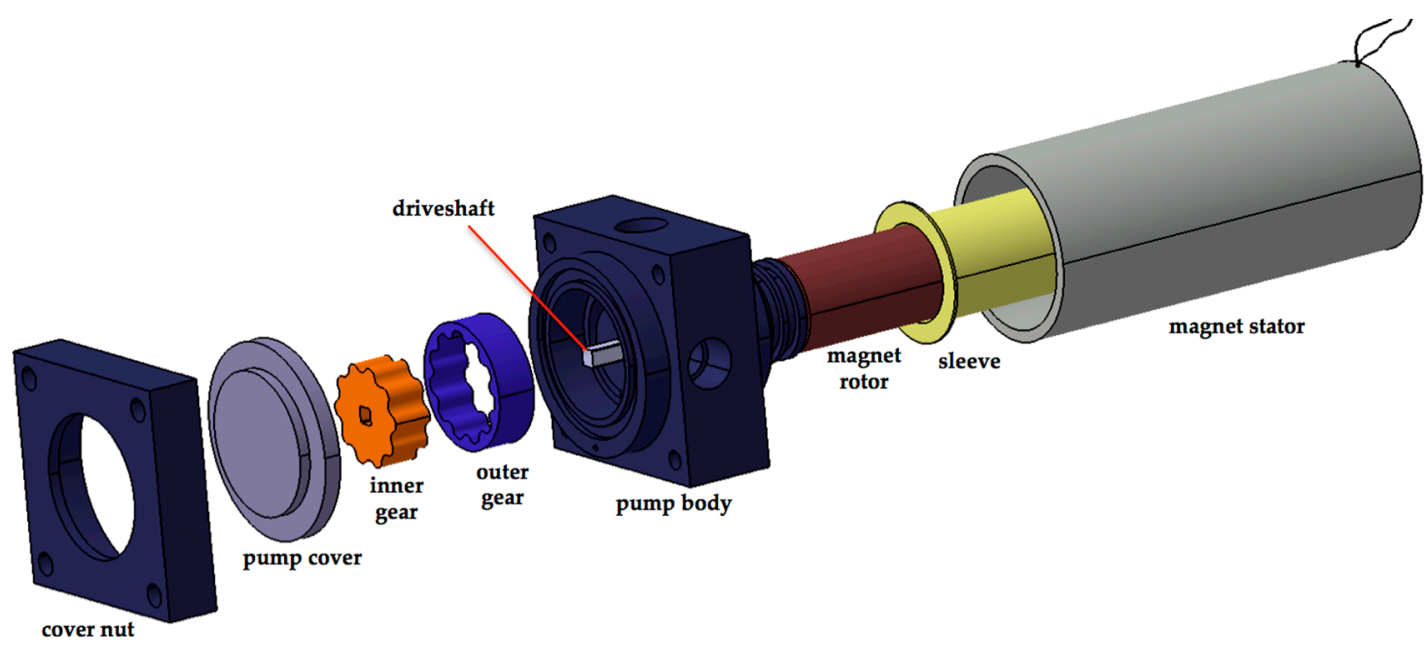

Figure 5. Three-Dimensional (3D)-CAD exploded view of the mini trochoidal-gear pump architecture.

Special attention is taken to enclose the ensemble. On one hand, the magnet stator is screwed in the pump body with two main functions: to tighten the sleeve against the pump body to guarantee the sealing and to ensure concentricity and minimum magnetic-gap between pole pieces, and to stator through the thin wall of the sleeve. On the other hand, the division into two covers, the pump cover and the cover nut, allows for a perfect flat fitting of the pump cover over both inlet and outlet gears, while a margin of axial clearance can be adjusted by means of the tight level of the cover nut. In this first prototype, there is no shadow porting carved on the pump cover.

The magnet rotor is coupled directly by a driveshaft to the inner gear. This is a decisive advantage of using an internal direct drive is the prevention of sealing the driveshaft.

The material of the pump body, pump cover, cover nut and driveshaft is the same, that is, steel of high quality. In this first prototype, steel was thought to be under control in the manufacturing 
process, surface roughness, and tolerance accuracy, as well as the temperature effects. The superficial roughness is $0.05 \mathrm{Ra}$ where the trochoidal-gear is allocated, the housing of the pump body, with a maximum tolerance in the external diameter of external gear of $20 \mu \mathrm{m}$. In the next step, the material of a second prototype will be aluminum, or similar alloy to be studied, thus reducing weight.

\subsubsection{Conception of the 'In-Out Sleeve Passageway' Configuration}

The sleeve embodies the magnet rotor becoming a hermetic set together with the pump body and pump cover filled with liquid (see Figure 6a). A tight magnet-gap is formed and intended for avoiding sliding contact between the sleeve and the magnet rotor, creating hydrodynamic lubrication helping to support it. The coaxially of each gear in its own rotation axis and its eccentricity is guaranteed by the guide provided by the pump body to the mechanical driveshaft connected to the inner gear. Then, the electro-magnetic driving on the magnet stator performs the necessary torque to the rotation.

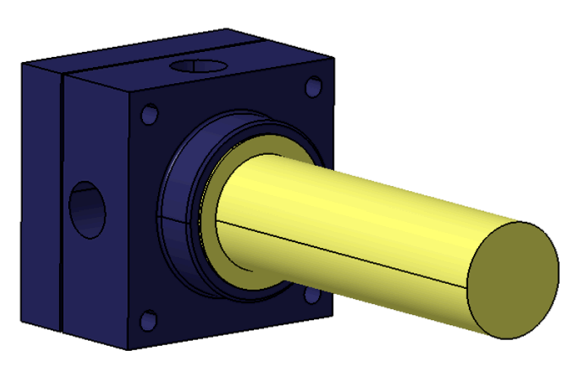

(a)

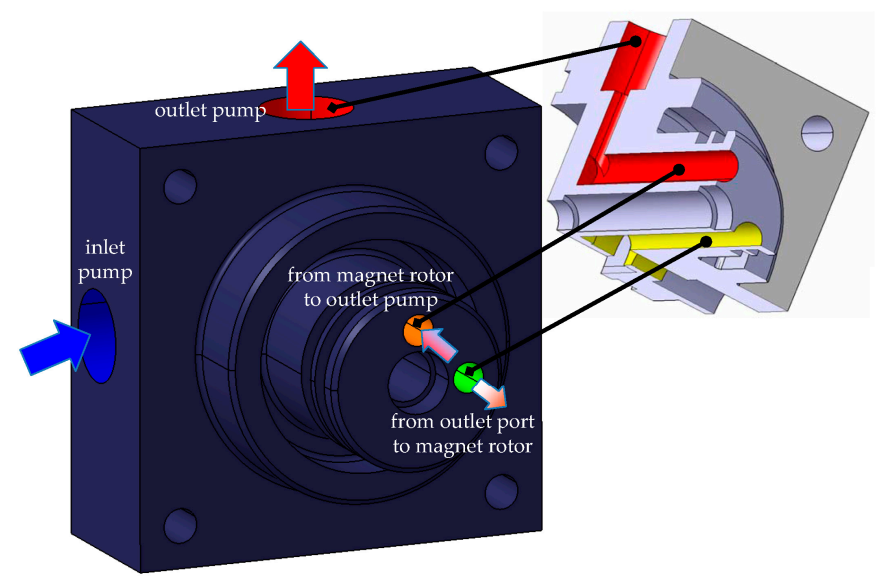

(b)

Figure 6. (a) Sealing of the magnet rotor by means of the sleeve, in yellow; (b) the 'in-out sleeve passegaway'.

The mTGp confronts then the main technological challenge of ensuring whole interior of the pump is filled and wetted with working fluid and the formation of the hydrodynamic film. The conception of this challenge is named 'in-out sleeve passageway' and it is schemed in Figure 6b. From the outlet port, the working fluid is not directly guided to the outlet of the pump, but it is redirected to the interior of the sleeve, from the outlet port to the magnet rotor through a smart conduction drilled in the pump body. Then, from the magnet rotor to the outlet of the pump, the working fluid is guided outside of the sleeve through another conduction drilled in the pump body.

Since the brushless motor is a part of the mini pump, the 'in-out sleeve passageway' additionally has the function of heat dissipation to ensure its operation within the defined temperature limits. Besides, the rotational movement of the magnet rotor is also helping the film formation and the pumping effect.

\subsubsection{The Surface and Coating Preparation}

A special treatment with the surface characteristics, the coating 'diamond-like-carbon' (DLC), has been performed on the pump body and pump cover in contact with the trochoidal-gear unit by FLUBETECH. DLC Molt is a 'physical vapor deposition' (PVD) coating based on multilayers of carbon compounds. The obtaining features and the multilayers sequence that DLC Molt coating presents, allows for achieving excellent benefits such as resistance towards adhesive and abrasive wear, less friction due to the tribology properties of carbon, absence of the dimensional distortions during the 
coating process, an increase of the lifetime while maintaining the original polish, and protection against scratches. Its technical characteristics are summarized in Table 3, and Figure 7 shows the result.

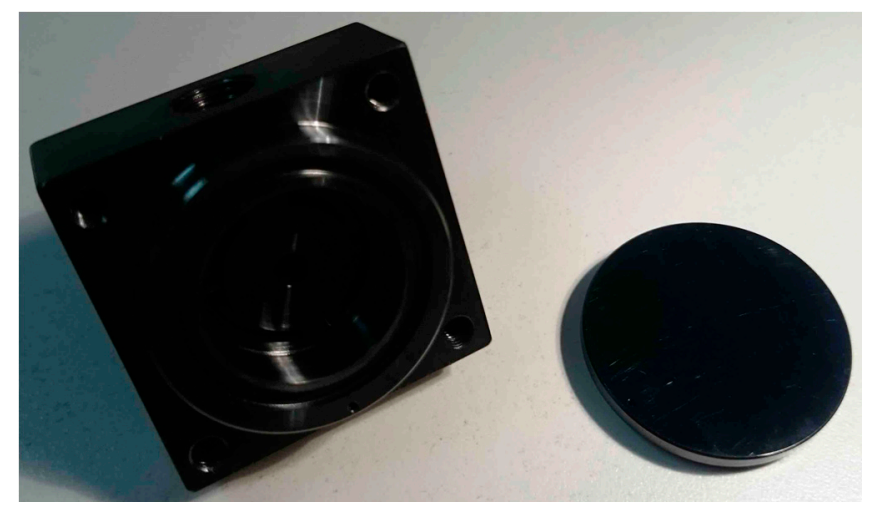

Figure 7. Pump body and cover after 'diamond-like-carbon' DLC Molt coating.

Table 3. DLC Molt technical characteristics.

\begin{tabular}{cc}
\hline Parameter & Value \\
\hline Hardness & $27 \mathrm{GPa}(2700 \mathrm{HV})$ \\
Friction Coefficient & 0.1 \\
Thickness & $3 \mu \mathrm{m}$ \\
Color & Anthracite black \\
Obtaining Temperature & $<250^{\circ} \mathrm{C}$ \\
\hline
\end{tabular}

\subsubsection{PJG-23v2 Magnet-Sleeve Brushless Motor}

The electrical motor is an ad hoc multipolar surface mounted permanent magnet-sleeve brushless motor model PJG-23v2 designed and manufactured by Mavilor Motors for the mini trochoidal-gear pump, as shown in Figure 8. The PJG-23v2 has deeply considered two imperative conceptions in its design. Firstly, the torque to rotate the gear set is not intended for working as a gearbox, but working as a part of a hydraulic pump. Secondly, the contact area arises between rotor-stator-fluid.

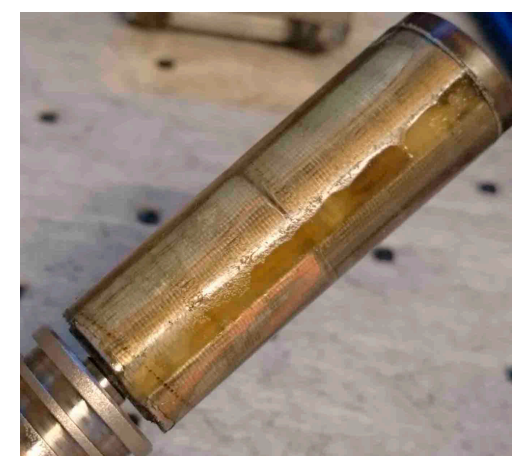

(a)

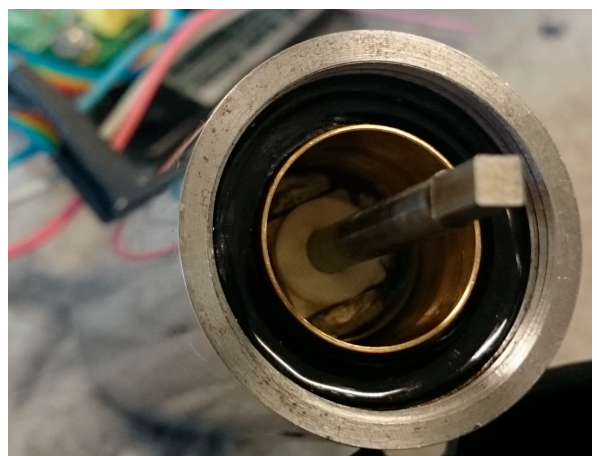

(b)

Figure 8. (a) Magnet rotor; (b) magnet stator and sleeve.

The PJG-23v2 is controlled by the sensorless drive Infranor EASY AK 230/17 + FCL EASY 230. The system is supplied for the tests with $48 \mathrm{Vdc}$ and a limit current of $5 \mathrm{~A}$ in a continuous mode. The power is analyzed by means of a Circuitor CVM-C10-ITF-485-ict2. Table 4 arranges the main motor data. 
Table 4. PJG-23v2 motor data of mTGp.

\begin{tabular}{cc}
\hline Characteristic & Value \\
\hline Maximum speed (bus 48 Vdc) & $2000 \mathrm{rpm}$ \\
Stall torque & $0.13 \mathrm{Nm}$ \\
Stall current & $1.47 \mathrm{~A}$ \\
Torque constant & $0.089 \mathrm{Nm} /(\mathrm{A} \cdot \mathrm{rms})$ \\
Voltage constant & $0.39 \mathrm{Vs} /(\mathrm{rad} \cdot \mathrm{rms})$ \\
Peak torque & $0.78 \mathrm{Nm}$ \\
Resistance ph-ph & $10.00 \Omega$ \\
Inductance ph-ph & $2.01 \mathrm{mH}$ \\
Inertia & $0.0025 \mathrm{~kg} \cdot \mathrm{m}^{2} \cdot 10^{-3}$ \\
Weight & $0.26 \mathrm{~kg}$ \\
Poles pairs & 4 \\
Insulation & Class F \\
\hline
\end{tabular}

\subsection{4. mTGp Prototype}

The ensemble of the mTGp prototype is shown in Figure 9. The prototype is intended to be the proof of concept and the technology demonstration with lab testing in an experimental test bench. Using an in-house pump cover manufactured with a transparent polymer, as shown in Figure 10, the first performance tests were carried out. The transparent pump cover allowed for directly seeing the operation of the prototype and also recording it with a high-speed video camera for slow motion analysis.

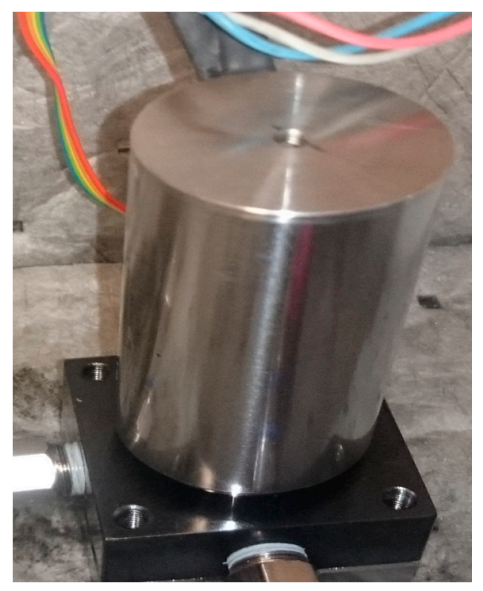

Figure 9. Pump embodiment of the mTGp prototype.

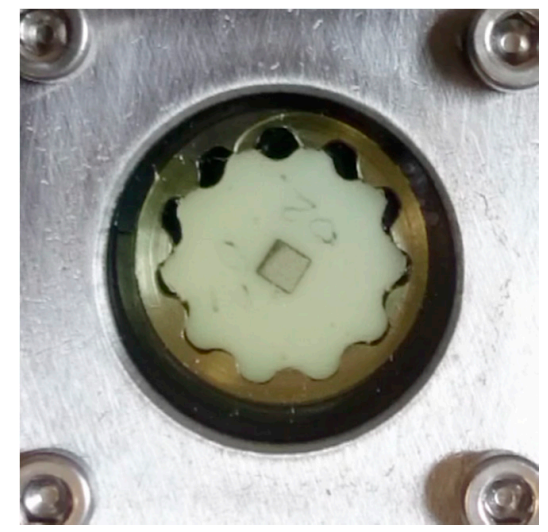

Figure 10. POM inner gear and sintered outer gear through an in house manufactured transparent polymer pump cover. 


\section{Instrumentation, Test Bench and Testing Procedure}

The experimental work carried out with the mini trochoidal-gear pump is intended to characterize the steady-state flow-pressure performance. A mini test bench is assembled which the hydraulic arrangement depicted in Figure 11.

The sensorless drive controls the rotational speed of the mini trochoidal-gear. The inlet $(\mathrm{p}, \mathrm{a})$ and outlet $(\mathrm{p}, \mathrm{i})$ dynamic pressure is measured by using a $\mathrm{PCB}^{\circledR}$ piezoelectric miniature dynamic pressure sensor model 113B21 with a measurement range of $0-1379 \mathrm{kPa}$ bar and sensitivity of $3.6 \mathrm{mV} / \mathrm{kPA}$. The inlet $(\mathrm{P}, \mathrm{a})$ and outlet $(\mathrm{P}, \mathrm{i})$ static pressure is measured by using a Unik ${ }^{\circledR} 5000$ pressure transducer with a measurement range of $0-2000 \mathrm{kPa}$ and a precision of $\pm 0.2 \% \mathrm{FS}$. The command signals, incoming inputs, and output signals are processed by means of a National Instruments ${ }^{\circledR}$ data acquisition device NI USB-6343. The acquisition system is completed via an ad hoc code based on LabView ${ }^{\circledR}$ software.

The working fluid is Hydrolubric ISO VG 32 hydraulic oil with a viscosity of $32 \mathrm{~mm}^{2} / \mathrm{s}$ at $40{ }^{\circ} \mathrm{C}$ and a density of $860 \mathrm{~kg} / \mathrm{m}^{3}$ measured with a hydrometer. A Kern ${ }^{\circledR}$ PCB 1000-2 precision balance with a weighing range of $1000 \pm 0.01 \mathrm{~g}$ (MFB) affords the measurement of the mass flow rate. This continuous signal is transferred to the computer by means of a serial communication RS-232C cable.

The working pressure is settled by a Wandfluh ${ }^{\circledR}$ manual direct operating valve (DOV). The experimental tests were performed at the constant temperature of $30^{\circ} \mathrm{C}$, measured with a PT100 resistance temperature detector $(\mathrm{T})$ in a two liters reservoir. Finally, before starting the experimental procedure, the working fluid was filtered at $5 \mu \mathrm{m}$ with a Millipore ${ }^{\circledR}$ vacuum filter holder to avoid any damage to hydraulic system components.

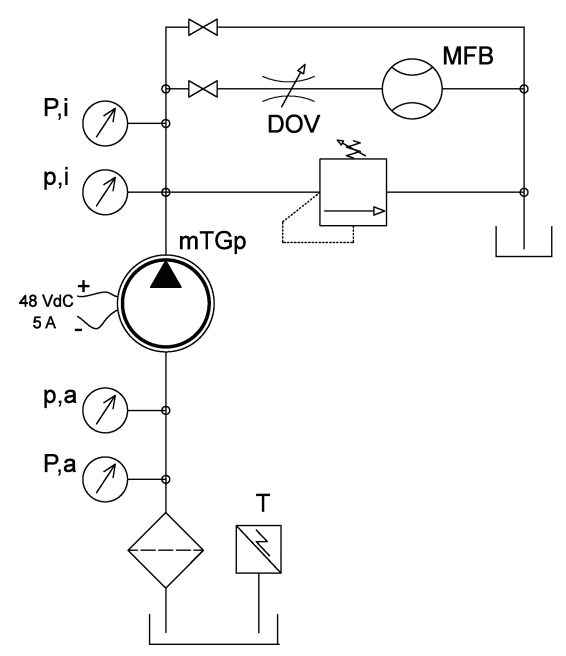

Figure 11. In-house mini test bench structure.

\section{Results and Discussion}

\subsection{Mini Trochoidal-Gear Theoretical Fluid-Mechanical Characteristics}

Fluid-mechanical characteristics are analytically simulated by means of GeroLAB Package System [29] under certain working conditions. Performance indexes such as the volumetric characteristics (chamber volume, volume variation, instantaneous flow, and irregularity flow index, as the rate between the difference of maximum-minimum volume and the average volume) and the maximum contact stress can then be obtained. The stress calculation is based on the premise of both gear axis fixed. When a small anti-clockwise rotation is applied to the inner gear, tooth deformations are large enough to provide contact forces on the active points whose combined moments are equal to the stress moment on the external gear. Finally, Hertz's equations are used to find the maximum contact stress. The volumetric characteristic with an irregularity flow index of $3.1 \%$ is obtained, as shown in Figure 12. 


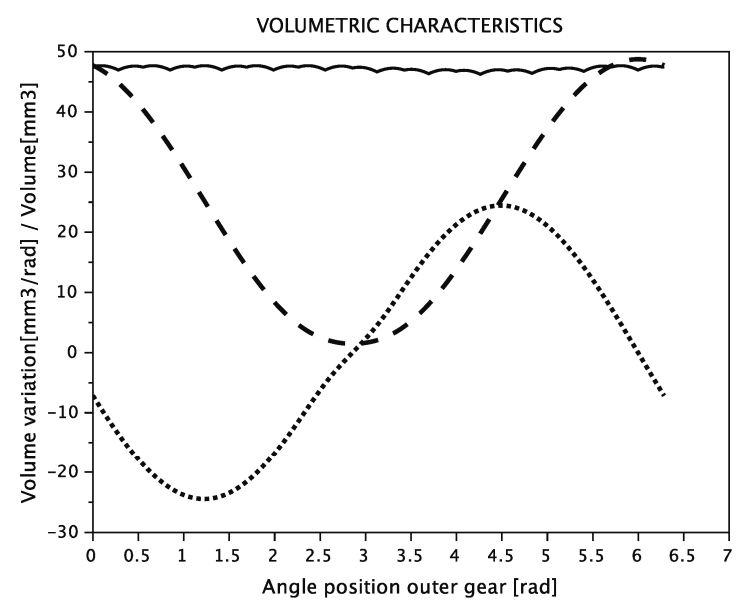

Figure 12. Volumetric characteristics: chamber volume (dash line), volume variation (dot line), and instantaneous flow (solid line) [29].

Figure 13a depicts the maximum contact stress history of the first contact point $\left(\mathrm{P}_{\mathrm{k} 1}\right.$ in Figure 1$)$ for a complete revolution of the outer gear with sintered metal inner gear at a maximum working pressure of $0.5 \mathrm{MPa}$. Furthermore, it can be compared once the inner gear is replaced by the POM inner gear, as shown in Figure $13 b$.

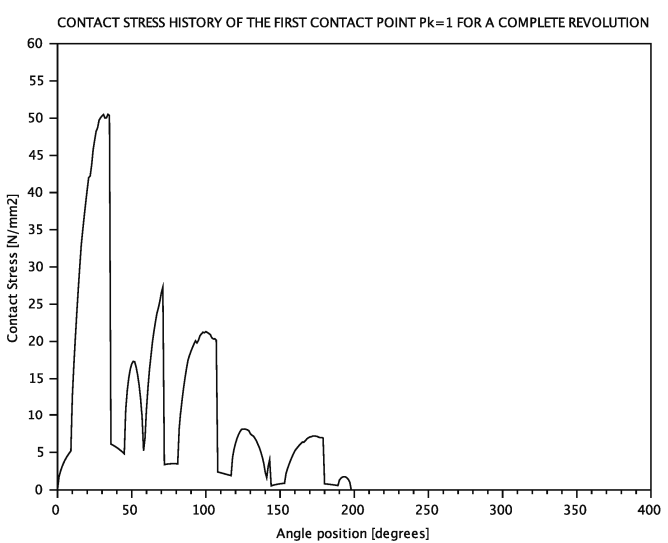

(a)

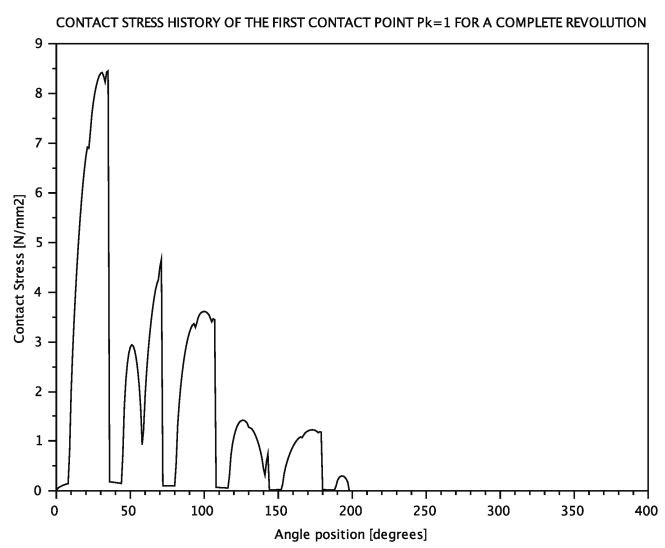

(b)

Figure 13. Contact stress history of the first contact point $\left(\mathrm{P}_{\mathrm{k} 1}\right.$ in Figure 1) for a complete revolution of the outer gear [29] (a) sintered metal inner gear; (b) POM inner gear. 


\subsection{Mini Trochoidal-Gear Pump Prototype Performance Indexes}

Up to $2000 \mathrm{rpm}$ rotational speed and 5 bar outlet pressure, the preliminary trials proof feasibility, and technical performance. Figure 14 shows the experimental results of volumetric efficiency, defined as the ratio between the measured and the theoretical flow rate $\left(=c_{v} \cdot \mathrm{rpm}\right)$, with the sintered metal mini trochoidal-gear set.

At all rotational speeds and low working outlet-inlet pressures, satisfactory indexes are reached over 0.9 , especially at the low speed of $500 \mathrm{rpm}$. Nonetheless, as the working outlet-inlet pressure setting arises, the volumetric efficiency significantly decreases. The gradient is undesirably pronounced and low volumetric efficiency indexes are reached for all rotational speeds. Definitely, this is the main backward performance of the mTGp prototype.

The volumetric efficiency is very low at $500 \mathrm{rpm}$ and 2 bar working pressure, predominantly, owing to the leakage happened in the axial gap of the trochoidal-gear and the housing of the pump body. When the trochoidal-gear tries to pump up to 2 bar counter-pressure with such low rotational speed, the fluid is mostly kept inside of the volume chambers. Besides, this particularly low rotational speed does not contribute much to the viscous effect in the dragging velocity of the fluid in contact with the trochoidal-gear. Here, the second main backward performance is the mechanical friction, on one hand, the cover nut must be tightly assembled to avoid leakage and increase the volumetric efficiency, but on the other hand, it penalizes the frictional performance of the unit. Then, a more powerful electrical motor unit is desirable.

Another important effect at low rotational speed is the difficulty to achieve an effective hydrodynamic effect and full film lubrication at all times of operation. However, from $500 \mathrm{rpm}$ to $1000 \mathrm{rpm}$, the double is the speed and the double is the volumetric efficiency, and an acceptable value of $80 \%$ for $2000 \mathrm{rpm}$ at 3 bar is reached. Subsequently, despite of the difficulties occurred and the several disappointed fallouts obtained, the main consequences of these results lay on the table the functionality of this novel concept as a mini trochoidal-gear pump of variable flow.

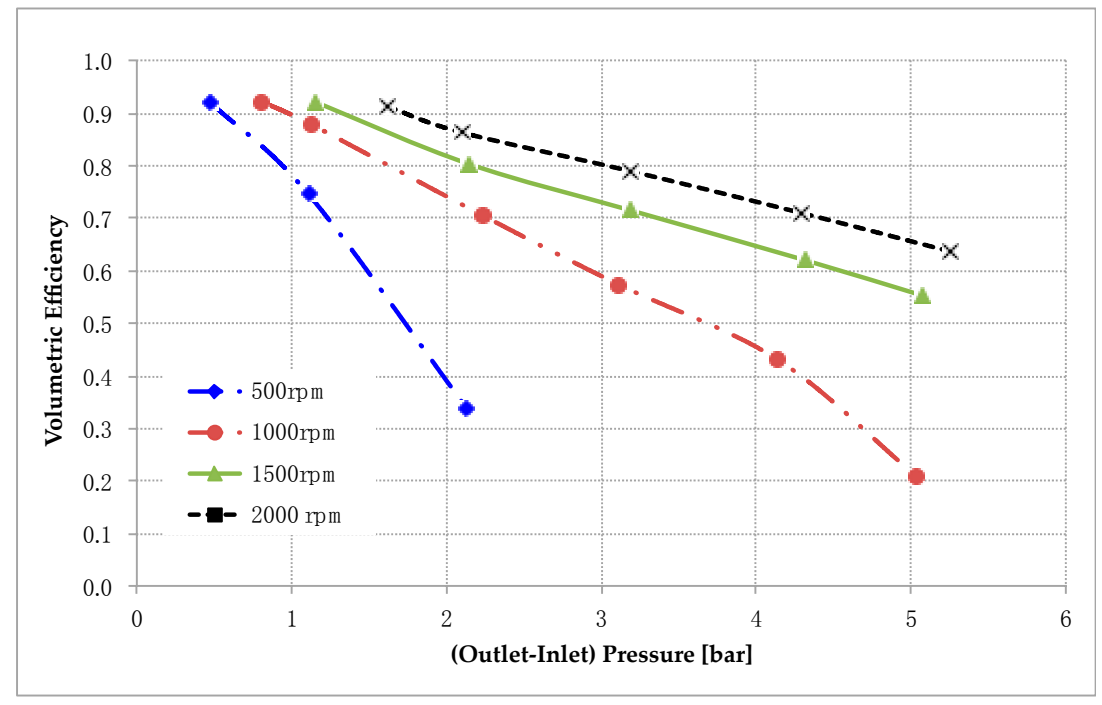

Figure 14. mTGp volumetric efficiency sintered metal inner gear performance with 'in-out sleeve passageway' configuration.

In order to test the efficacy of the 'in-out sleeve passageway', a standard outlet port configuration was also manufactured in the pump body, as illustrated in Figure 15. This configuration could allow bi-directional work. Then, with the same inlet port but cancelling the functionality of the 'in-out sleeve passageway' configuration, as shown by crosses in Figure 15, volumetric efficiency indexes 
are compared in Figure 16. By analyzing these results, the efficacy of the 'in-out sleeve passageway' concept is proven.

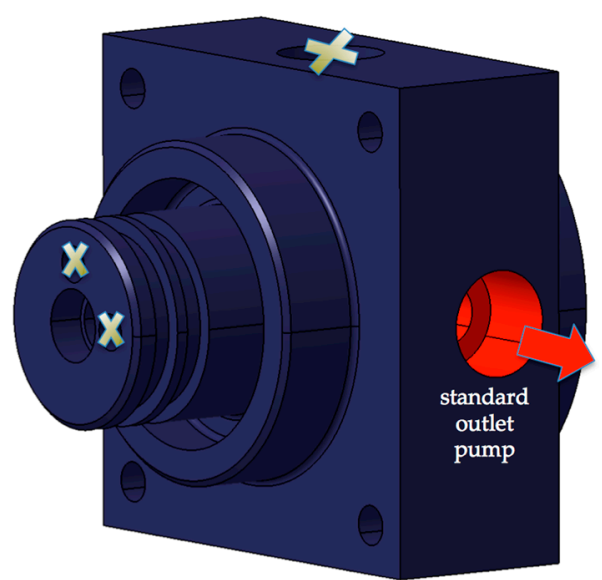

Figure 15. Standard outlet port configuration.

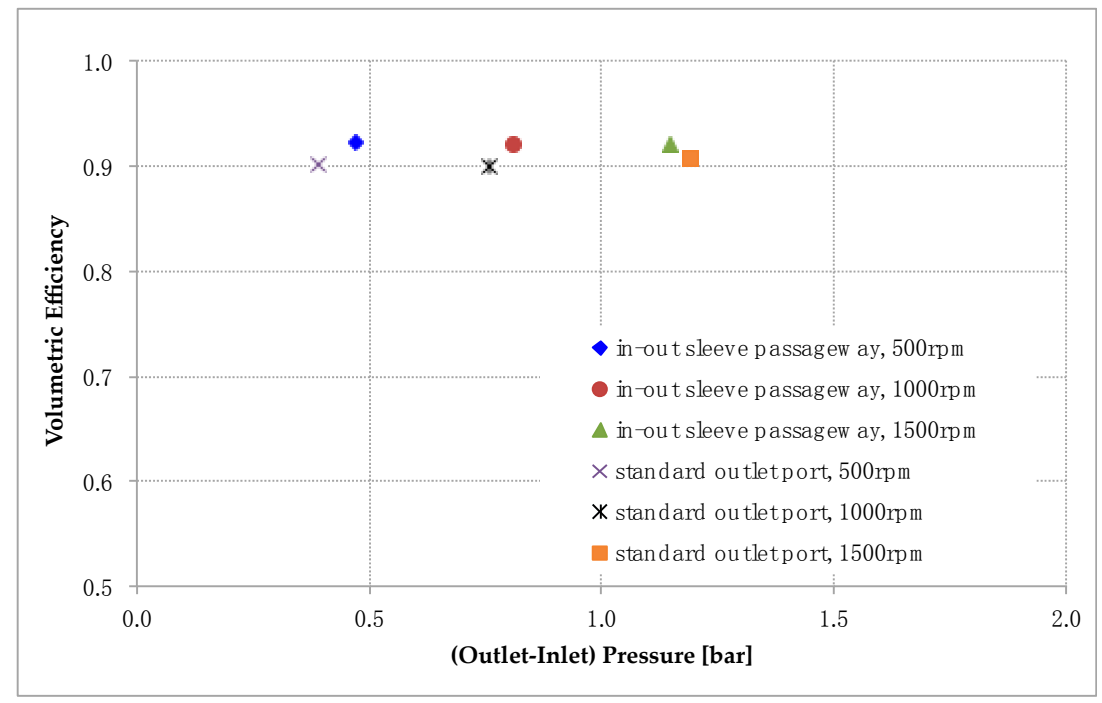

Figure 16. mTGp volumetric efficiency sintered inner gear performance comparison between 'in-out sleeve passageway' and standard outlet port configuration.

A posteriori, the POM inner gear replaces the sintered metal one and tested in the mTGp by the 'in-out sleeve passageway' configuration. The volumetric efficiency indexes are shown in Figure 17. A suitable quality behavior of the steady-state flow rate and the working pressure for the POM inner gear is revealed. Although, the volumetric efficiency values are around 10-15\% lower as compared to the sintered metal, it can be expected within reasonable bounds, good performance pending of future work.

A disappointment was the impossibility of making to work the whole of the POM mini trochoidal-gear unit, specifically the POM outer gear. It is believed that the surface finishing, roughness, and tolerances have to be improved, together with the enhancement of the electrical motor performance, as it was previously exposed. Moreover, the outer gear could rotate guided in the interior of a bearing seat made of bronze located in the pump housing in continuous sliding contact of its external wall of perimeter $\pi D_{c}$ and thickness $H$ [23]. Nonetheless, the future work is promising. 


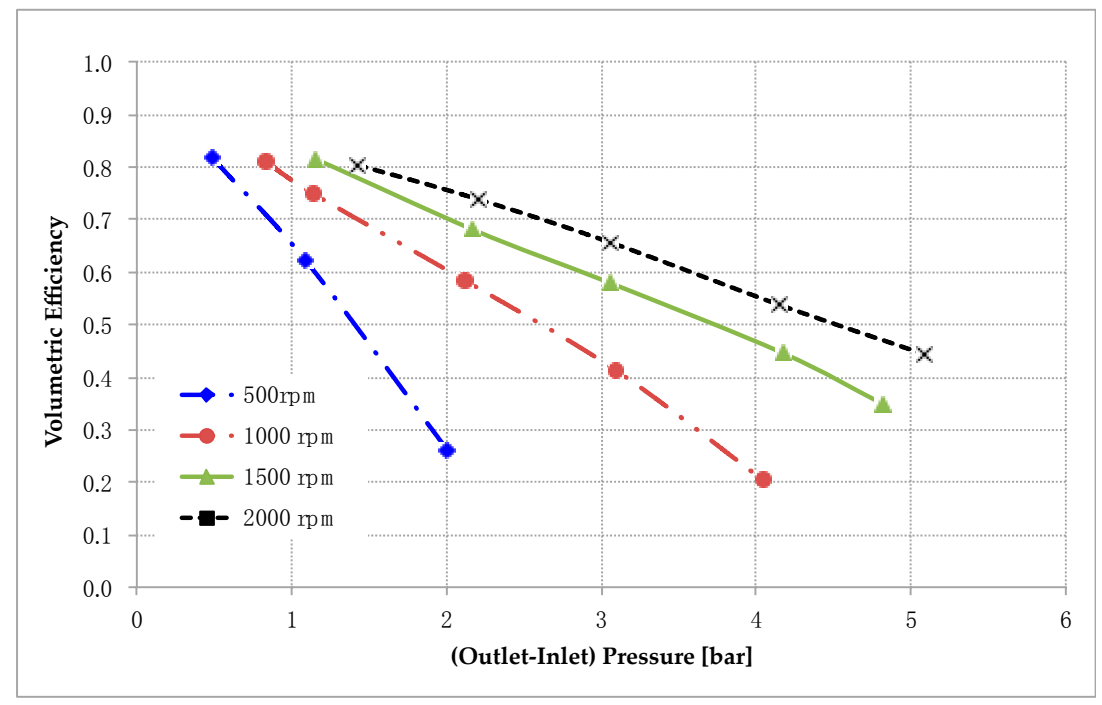

Figure 17. mTGp volumetric efficiency POM inner gear performance with 'in-out sleeve passageway' configuration.

\subsection{Numerical Study and Simulation Results}

Although the main goal of the presented work is the development of a new mini trochoidal-gear pump prototype rather than a numerical study of the pump, results have been compared with numerical simulation and experimental work.

A new approach based on the open source tool OpenFOAM ${ }^{\circledR}$ [32] was presented by Castilla et al. [28] for the 3D Computational Fluid Dynamics (CFD) simulation of a mini gerotor pump working at a low pressure by using the standard outlet port configuration. The total pressure is set in inlet and outlet, and fluctuations are due to a flow rate produced by teeth and internal impedance. Neglecting the impedance of pipes in the experimental mini test bench, this domain can be considered equivalent. Summarizing, the main achievements were: (i) The development of a novel methodology to simulate the complex flow processes in a mini gerotor pump, specially interteeth, and axial clearances; (ii) The performance evaluation of the mesh approach and the new boundary conditions, the comparative of theoretical and numerical flow ripple with the interteeth contact condition, and the pressure distribution in the axial clearance; (iii) The verification of initial performance results with the numerical study and experimental work of a first prototype by means of a mini test bench. Moreover, two main contributions could also point out for the performance of the numerical simulation. On one hand, a contact point viscosity model is used for the simulation of solid-solid contact between gears in order to avoid the teeth tip leakage and simulate actual interteeth contact [30]. On the other hand, a new boundary condition was implemented for the gear mesh points motion in order to keep the mesh quality while moving gears with relative velocity [30].

For $1000 \mathrm{rpm}$ and 1 bar of counter-pressure, a good agreement in volumetric efficiency estimation and pressure fluctuations have been found, as shown in Figure 18, where the pressure ripple has been also compared between the numerical approach and experimental measurement. The pressure fluctuations band extension agrees very well, although it seems that the CFD calculation is not able to correctly capture the overpressure at the beginning of the gearing cycle, probably due to the lack of compressibility and turbulence models in the CFD simulations. The decay of the pressure at the beginning of the gearing cycle matches the leakage increase observed in beginning and ending of the gearing period. Unfortunately, the agreement is not nearly as good for higher counter pressures, probably because of the mini size dimensions and the future work is being carried out to improve it. 


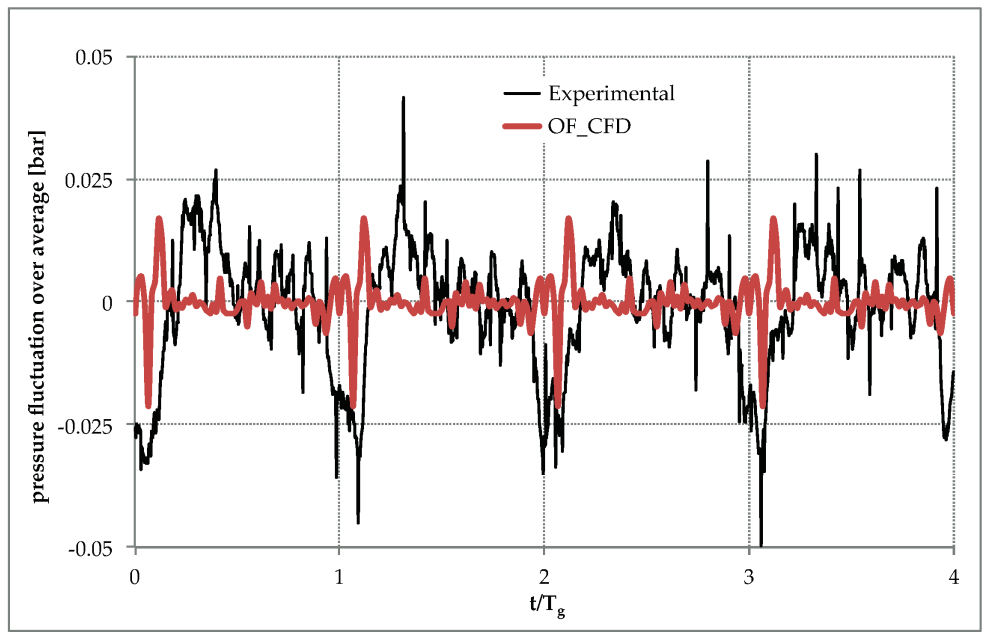

Figure 18. Experimental and computational flow ripple time series at outlet pressure port for $1000 \mathrm{rpm}$ and 1 bar of working pressure. Pressure data are fluctuations over average pressure ( 1 bar). Time has been normalized with gearing period $T_{g}=1 /(Z-1) \cdot r p m$.

\section{Conclusions}

The investigation conducted in this paper is the technology development of a progressive concept of trochoidal-gear technology: a sealed non-exterior driveshaft mini gerotor pump with a magnet-sleeve driving rotor. This research intends to show the laborious and challenging journey from the original concept to the first prototype, where the theoretical approach is not always directly reflected in the prototype performance results.

Formerly, early in the design process from a standard-commercial mini trochoidal-gear set, basic performance and dimensional requirements have been evaluated, becoming the key parameters that led to the configuration of the mini trochoidal-gear pump architecture: mTGp.

The mTGp confronts the main technological challenge of being sealed with a non-exterior driveshaft, ensuring the whole interior of the pump was filled and wetted with working fluid. The conception of this challenge is named 'in-out sleeve passageway' and helps the hydrodynamic film formation, the pumping effect, and the heat dissipation. The ultimate stage of this design process has been the manufacture of the hydraulic parts of the mini pump together with the ad hoc multipolar surface mounted permanent magnet-sleeve brushless motor. The final ensemble is the technology demonstration validated with experimental work in a well-instrumented mini test bench.

The trend of applications of polymer composite materials and their benefits are assessed in this trochoidal-gear technology application. From the analysis of previous works, the decision of choosing as polymer the pure polyoxymethylene (POM) is based on, among others, its high strength and stiffness, accessibility on the market, and its low price. Then, a POM mini trochoidal-gear unit was manufactured and the inner gear was tested.

This novel variable flow pump configuration, despite the difficulties that occurred and several disappointed fallouts obtained, such as frictional performance of the trochoidal-gear units, accomplishes a standard volumetric flow rate at a low rotational speed with satisfactory volumetric efficiency. Experimental results prove feasibility as well as proof of concept.

Finally, previous numerical simulation results and experimental work have been compared. A good agreement has been found in volumetric efficiency estimation and with regard to the pressure ripple, band extension agrees very well, although it seems that the numerical calculation is not able to correctly capture the overpressure at the beginning of the gearing cycle.

As a next step, the technology readiness has still to evolve to system development and field test with other operating conditions, where a most powerful electrical motor unit is desirable. Moreover, a step forward in the polymer composite in the trochoidal-gear technology has started in the mini size, 
though surface finishing, roughness and tolerances have to be improved. This mini pump prototype is believed to lead to a cleaner and noiseless hydraulic technology to be part of a wider part of sectors. Hence, important advantages can be foreseen.

The most forthcoming future work is to overcome the high mechanical friction and perform new experimental tests with a complete POM gear set. Besides, another POM gear set with new geometrical parameters is being designed and manufactured to be working in a new body pump. As well, using the pure POM and adding other ingredients such as glass or carbon fiber, it is possible at the next stage of work to obtain new materials of different qualities.

Acknowledgments: This research program, project DPI2013-42031-P, receives financial support from the Ministry of Economy and Competitiveness of Spain and is co-financed by FEDER founding of EU; authors acknowledge this financial support. This research program received funds for covering the costs to publish in open access. The authors thankfully acknowledge the computer resources at Magerit and the technical support provided by Centro de Supercomputación y Visualización de Madrid-Universidad Politécnica de Madrid (RES-FI-2017-2-0005). The authors also would like to acknowledge the companies AMES and MAVILOR for providing the necessary support, and FLUBETECH for the DLC Molt coating. The authors would like to thank Mr. Carlos Rio for manufacturing the transparent polymer pump cover.

Author Contributions: Pedro Javier Gamez-Montero conceived and designed the magnet-sleeve-sealing mini trochoidal-gear pump; Robert Castilla conceived and executed the numerical study. Javier Freire designed and performed the experiments; Pedro Javier Gamez-Montero and Esteve Codina analyzed the data; Piotr Antoniak, Justyna Krawczyk and Jaroslaw Stryczek designed and manufactured the POM mini trochoidal-gear unit and also analyzed the data; Pedro Javier Gamez-Montero and Piotr Antoniak wrote the paper.

Conflicts of Interest: The authors declare no conflict of interest. The founding sponsors had no role in the design of the study; in the collection, analyses, or interpretation of data; in the writing of the manuscript, and in the decision to publish the results.

\section{References}

1. Klopsch, V.; Germann, T.; Seitz, H. Numerical simulation of low-pulsation gerotor pumps for use in the pharmaceutical industry and in biomedicine. Curr. Dir. Biomed. Eng. 2015, 1, 433-436. [CrossRef]

2. Ivantysyn, J.; Ivantysynova, M. Hydrostatic Pumps and Motors; Academic Books International: New Dehli, India, 2001.

3. Gamez-Montero, P.J.; Castilla, R.; Codina, E. Methodology based on best practice rules to design a new-born trochoidal-gear pump. Proc. Inst. Mech. Eng. Part C J. Mech. Eng. Sci. 2017. [CrossRef]

4. Thiagarajan, D.; Vacca, A. Mixed Lubrication Effects in the Lateral Lubricating Interfaces of External Gear Machines: Modelling and Experimental Validation. Energies 2017, 10, 111. [CrossRef]

5. Rundo, M.; Corvaglia, A. Lumped Parameters Model of a Crescent Pump. Energies 2017, 9, 876. [CrossRef]

6. Stryczek, J.; Antoniak, P.; Jakhno, O.; Kostyuk, D.; Kryuchkov, A.; Belov, G.; Rodionov, L. Visualisation research of the flow processes in the outlet chamber-Outlet bridge-Inlet chamber zone of the gear pumps. Arch. Civ. Mech. Eng. 2015, 15, 95-108. [CrossRef]

7. Altare, G.; Rundo, M. Computational Fluid Dynamics Analysis of Gerotor Lubricating Pumps at High-Speed: Geometric Features Influencing the Filling Capability. J. Fluids Eng. 2016, 128, 111101. [CrossRef]

8. Altare, G.; Rundo, M. Advances in simulation of gerotor pumps: An integral approach. Proc. Inst. Mech. Eng. Part C J. Mech. Eng. Sci. 2017, 231, 1221-1236. [CrossRef]

9. Pellegri, M.; Vacca, A.; Frosina, E.; Buono, D.; Senatore, A. Numerical analysis and experimental validation of Gerotor pumps: A comparison between a lumped parameter and a computational fluid dynamics-based approach. Proc. Inst. Mech. Eng. Part C J. Mech. Eng. Sci. 2016. [CrossRef]

10. Pellegri, M.; Vacca, A.; Dautry, E.; Ginsberg, B. A Lumped Parameter Approach for GEROTOR Pumps: Model Formulation and Experimental Validation. In Proceedings of the 10th IFK International Fluid Power Conference, Dresden, Germany, 8-10 March 2016; pp. 465-476.

11. Frosina, E.; Senatore, A.; Buono, D.; Santato, L. Analysis and simulation of an oil lubrication pump for internal combustion engines. J. Fluids Eng. 2015, 137, 051102. [CrossRef]

12. Buono, D.; Siano, D.; Frosina, E.; Senatore, A. Gerotor pump cavitation monitoring and fault diagnosis using vibration analysis through the employment of auto-regressive-moving-average technique. Simul. Model. Pract. Theory 2017, 71, 61-82. [CrossRef] 
13. Gamez-Montero, P.J.; Castilla, R.; Codina, E.; Freire, J.; Morató, J.; Sanchez-Casas, E.; Flotats, I. GeroMAG: In-House Prototype of an Innovative Sealed, Compact and Non-Shaft-Driven Gerotor Pump with Magnetically-Driving Outer Rotor. Energies 2017, 10, 435. [CrossRef]

14. Garcia-Vilchez, M.; Gamez-Montero, P.J.; Codina, E.; Castilla, R.; Raush, G.; Freire, J.; Rio, C. Computational fluid dynamics and particle image velocimetry assisted design tools for a new generation of trochoidal gear pumps. Adv. Mech. Eng. 2015, 7. [CrossRef]

15. Raush, G.; Gamez-Montero, P.J.; Castilla, R.; Codina, E. Experimental study on the impulsion port of a trochoidal wheeled pump. Flow Meas. Instrum. 2017, 55, 13-22. [CrossRef]

16. Hsieh, C.F. Flow characteristics of gerotor pumps with novel variable clearance designs. J. Fluids Eng. 2015, 137, 041107. [CrossRef]

17. Ivanović, L. Reduction of the maximum contact stresses by changing geometric parameters of the trochoidal gearing teeth profile. Meccanica 2016, 51, 2243-2257. [CrossRef]

18. Ivanović, L.T.; Veličković, S.N.; Stojanović, B.Ž.; Kandeva, M.; Jakimovska, K. The selection of optimal parameters of gerotor pump by application of factorial experimental design. FME Trans. 2017, 45, 159-164. [CrossRef]

19. Nag, A.; Maiti, R. Unification of epitrochoid origin profile design approaches for external lobed star member used in hydrostatic and gear units. Proc. Inst. Mecha. Eng. Part C J. Mech. Eng. Sci. 2013, 227, 299-310. [CrossRef]

20. O'Shea, C. Hydraulic Flow Ripple Cancellation Using the Primary Flow Source. In Proceedings of the BATH/ASME 2016 Symposium on Fluid Power and Motion Control, American Society of Mechanical Engineers, Bath, UK, 7-9 September 2016; p. V001T01A044.

21. Miladinović, S.; Ivanović, L.; Blagojević, M.; Stojanović, B. The development of magnetic gears for transportation applications. Mobil. Veh. Mech. 2017, 43, 41-55.

22. Stryczek, J.; Banaś, M.; Krawczyk, J.; Marciniak, L.; Stryczek, P. The fluid power elements and systems made of plastics. Procedia Eng. 2017, 176, 600-609. [CrossRef]

23. Stryczek, J.; Bednarczyk, S.; Biernacki, K. Gerotor pump with POM gears: Design, production technology, research. Arch. Civ. Mech. Eng. 2014, 14, 391-397. [CrossRef]

24. Mancini, S.D.; Santos Neto, A.D.O.; Cioffi, M.O.H.; Bianchi, E.C. Replacement of metallic parts for polymer composite materials in motorcycle oil pumps. J. Reinf. Plast. Compos. 2017, 36, 149-160. [CrossRef]

25. Rodionov, L.; Rekadze, P. Experimental Vibroacoustic Research of a Gear Pump Made of different Materials. Procedia Eng. 2017, 176, 636-644. [CrossRef]

26. Mancò, S.; Nervegna, N.; Rundo, M.; Margaria, M. Miniature gerotor pump prototype for automotive applications. In Proceedings of the 3rd IFK International Fluid Power Conference, Aachen, Germany, 5-6 March 2002; pp. 153-167.

27. Gamez-Montero, P.J.; Castilla, R.; Buza, A.; Khamashta, M.; Codina, E. Numerical Study in a Mini Trochoidal-Gear Pump With Multi-Meshing Contact Points. In Proceedings of the BATH/ASME 2016 Symposium on Fluid Power and Motion Control, American Society of Mechanical Engineers, Bath, UK, 7-9 September 2016; p. V001T01A012.

28. Castilla, R.; Gamez-Montero, P.J.; Raush, G.; Codina, E. Method for Fluid Flow Simulation of a Gerotor Pump using OpenFOAM. J. Fluids Eng. 2017, 139, 111101. [CrossRef]

29. Gamez-Montero, P.J.; Castilla, R.; Mujal, R.; Khamashta, M.; Codina, E. GEROLAB Package System: Innovative Tool to Design a Trochoidal-Gear Pump. J. Mech. Des. 2009, 131, 074502. [CrossRef]

30. GeroLAB Package System. Available online: http:/ / www.gerolab.es (accessed on 16 September 2017).

31. Stryczek, J.; Bednarczyk, S.; Biernacki, K. Strength analysis of the polyoxymethylene cycloidal gears of the gerotor pump. Arch. Civ. Mech. Eng. 2014, 14, 647-660. [CrossRef]

32. The OpenFOAM Fundation, OpenFOAM, User's Guide Version 4.1. 2017. Available online: http:/ / www. openfoam.org (accessed on 15 August 2017).

(C) 2017 by the authors. Licensee MDPI, Basel, Switzerland. This article is an open access article distributed under the terms and conditions of the Creative Commons Attribution (CC BY) license (http:/ / creativecommons.org/licenses/by/4.0/). 